\title{
Границы знания как границы компетенции разума в культуре
}

\begin{abstract}
Аннотация: Предметом исследования выступают внешние и внутренние границы науки, определяющие метаморфоз превращенных, ненаучных форм знания на границах науки. Объект исследования - взаимоотношение науки и ненаучных форм знания в диахронном и синхронном измерениях.Особое внимание уделяется исследованию границ, за которые не может (и не должна) простираться "работа науки», которая переходит не столько в поиск ограничений компетенции разума, сколько в горизонт нравственной ответственности ученого. Сучетом данных реалий проблематика границ в научном и ином знании оказывается связанной с культурой рациональности, приобретая в новых условиях дополнительную актуальность. Обосновывается, что деструктивные черты техногенной циивилизации, где наука играет роль инновационного социокода, служат достаточным основанием для эпистемологической программы выявления границ компетенции разума, поставленной в свое время И. Кантом. Основным методом работы послужил классический метод диалектики, поскольку он имеет дело с особым способом рассмотрения сущего в широком онтологическом, гносеологическом и культурно-историческом контекстах. Также по мере необходимости нами использовались феноменологчческий, герменевтический и системный принципы, тезаурусный и контекстный подходы понимания и интерпретации культурных феноменов. С позиции автора, философская рефлексия границ науки и «другого» знания несомненно актуальна и для понимания того факта, что нет мира «чистой» науки и «чистого» рационализма: «мир науки» включает в себя все многообразие других, отличных от «чисто научных» форм знания (миф, теологчческие представления, интуицию, мистический, эзотерический опыт), равно как и все формы знания в известной мере рациональны (последняя рождается вместе с разумом). - Везде мы наблюдаем метаморфоз, взаимопревращение, взаимозаменяемость, восполняемость всех форм знания на границах науки и ненауки.
\end{abstract}

Ключевъе слова: Знание, наука, культура, статус кво, этическая рациональность, биосферная этика, глобальные проблемы человечества, «другое знание», границы знания, метаморфоз.

Review: The subject of the research is the external and internal boundaries of science which define metamorphosis of non-scientific forms of knowledge at the boundaries of science. The object of the research is the relationship between science and non-scientific forms of knowledge from the point of view of their diachronic and synchronic dimensions. Special attention is paid to the boundaries outside which science cannot and should not be spread. It is due to the scientist's responsibility rather than the limits of the mind competence. Taking this into account, the problem of the boundaries of scientific or any other knowledge is related to the culture of rationality and thus acquires additional importance under new circumstances. The author of the article proves that destructive features of the industrial civilization where science plays the role of the innovative social code constitute grounds for the epistemological program of defining the boundaries of mind competence as it was introduced by Immanuel Kant. The main research method used by the author is the classical method of dialectics. This method allows to view the matter from the points of view of ontology, gnoseology, culture and history. When it was necessary, the author has also applied the phenomenological, hermeneutical and systems concept, thesaurus and contextual approaches to understanding and interpreting cultural phenomena. According to the author, philosophical interpretation of the boundaries of science or any 'other' knowledge is also important to understand the fact that there is no 'pure' science or 'pure' rationalism: the world of science involves a variety of other forms of knowledge (myth, theological concepts, intuition, mystical or esoteric experience); and all forms of knowledge are rational to a certain extent. In all cases metamoprhosis, interconversion and compatibility of all forms of knowledge at the boundaries of science and non-science can be observed. The article is devoted to philosophical problematic of the frontiers of scientific and other knowledge in the phenomenology of contemporary culture. Its leading sense acts to set the frontiers of science and 
other knowledge on the basis of ethical rationality and Biosphere ethics with a view to promoting the humanistic orientation of modern mankind in order to preserve the status quo and the intrinsic value of life itself.

Keywords: Metamorphosis, boundaries of knowledge, 'other knowledge', global humanity issues, Biosphere ethics, ethic rationality, status quo, culture, science, knowledge.

$\Pi$ режде всего отметим, что в широком плане философская проблематизация заявленной темы лежит в проблемном поле рефлексии разума и связывается нами с достаточно зримым противоречием, отсылающим нас к онтологии современного человечества. Его суть состоит в том, что, с одной стороны, на фоне современных глобальных проблем очевидна (можно сказать, назрела) необходимость задать этические границы науки и другого знания. Причем, независимо от его гносеологического/ эпистемологического/ статуса. А с другой стоны, мы констатируем недостаточный уровень осознания значимости данной задачи в обществе, недостаточную разработанность оптимальных механизмов ее практической реализации во имя сохранения статуса кво, абсолютной ценности человеческой (как впрочем, и любой) жизни. А между тем, сегодня это вопрос первостепенной важности. В данной связи предпримем попытку аналитики наиболее значимых аспектов, связанных с актуализацией границ компетенций современного «рацио». Они и составят проблемно-теоретическое «тело» нашей статьи. Сразу уточним: понятие границ мы употребляем в значении меры, предела возможного и допустимого в научно-познавательной и творческой деятельности. [1, с. 132].

Очевидные деструктивные черты современной техногенной цивилизации, где наука играет основополагающую роль, служат достаточным основанием для того, чтобы первый аспект актуальности связать с задачей ограничения компетенции разума, поставленной в свое время И. Кантом [2, с. 339]. Ее решение лежит в области своевременного выявления и оперативного разрешения глобальных социально значимых проблем особого «таймированного» класса (выражение М.К. Петрова) с привлечением всего комплекса знания, с повышением социальной ответственности ученых и разумного использования наличного знания живущим сегодня поколением людей [3, с. 229]. Тем самым задача исследования границ, за которые не может и не должна) простираться «работа» научного знания (по Канту), переходит в стадию ограничения компетенции разума, смещаясь при этом в центр гносеологических исследований. В противном случае таймированная проблематика имеет шансы приобрести зловещий оттенок общечеловеческой катастрофы, свидетельствуя «в пользу» инфляции разума.

Второй аспект остроты проблемы границ знания и познания лежит в области необходимости выработки подлинной культуры рациональности. Это связано с тем фактом, что крайняя рационализация техногенной культуры стимулирует так называемые «психологические эпидемии», когда вытесненное чрезмерной рационализацией «иррациональное» перерастает в стадию «оккультного ренессанса», или "религиозного возрождения», сопровождаясь вседозволенностю «без берегов», отступлением от принципа «не навреди» с негативными последствиями, затрагивающими сферу человеческой духовности и телесности. С учетом данных реалий проблематика границ знания в научном и ином знании (равно как и в любом виде человеческой деятельности) оказывается связанной с культурой рациональности (как способа познания и деятельности), приобретая в новых условиях рефлексивности дополнительную актуальность именно с данных позиций.

Третий аспект в значительной мере определяется общей направленностью современной гносеологической проблематики, в эпицентре которой - вопрос об определении статуса постнеклассической науки, ее потенциале (или его отсутствии), резонирующий с проблемой рассогласования науки с базисными ценностями культуры. В неклассической эпистемологии преодоление данного разрыва связывается с необходимостью реконструирования базового понятия «рациональность» с тем, чтобы задать его новые границы и горизонты в соответствии с требованиями, выдвигаемыми современной научной практикой. Так, например, рассмотрение новых неклассических тенденций и подходов, связанных с формированием нового типа науки, показало, 
что в значительной мере новый тип научной рациональности («рациональности особого рода») задается (и стимулируется) когнитивной стратегией постмодернистской парадигмы, утверждающей легитимность плюралистического видения реальности и развитие множественности познавательной деятельности. Основные тенденции здесь состоят: в выявлении неклассических смыслов основных понятий классической теории познания; в поиске новых оснований для реконструирования понятия «рациональность»; в разработке интегральной концепции рациональности; в признании комплементарного характера разных концепций истины; в возможности совмещения классического понятия истины с признанием теоретической нагруженности фактов и культурно-исторического характера субъекта познания; в утверждении концепции нетрадиционной науки и идеи «единой науки». Прообразом «новой» рациональности становится смесь духовности и религиозности, относительность (релятивизм), синергия и другие варианты.

Надо сказать, что особая роль в этих процессах возлагается на методологическое сознание и методологическую культуру ученого, на углубленную работу по анализу и рефлексии характера, границ научной деятельности с учетом прежде всего гуманитарной и социальной природы изучаемых явлений. Тем самым научной рациональности придается инструментарность философского разума. Концепт же нового типа рациональности становится возможным на пути синтеза философского разума и научной рациональности. В данном контексте перспективные стратегии науки ближайшего будущего принципиально связываются нами с необходимостью изменения самой концепции понимания науки и идеала научности соответственно. Здесь особый интерес для нас представляют оригинальные подходы в сфере формирования научных представлений. В частности, концепция А.Г. Дугина, который различные типы рациональности (сакральную, монотеистическую и секулярную, соответственно - парадигмы сферы, луча и отрезка) связывает с эволюцией взглядов человечества на природу мира и мышления [4, с. 119] . Автор предлагает принципиально новую классификацию этапов развития науки и философии науки и техники в соответствии с критериями, отличными от общепринятых, которые исходят из принципа однонаправленного исторического развития научных знаний и поступательного их накопления, показывая, что такой чисто количественный подход к истории науки оставляет без объяснения множество несоответствий, обычно либо истолковываемых с помощью натяжек, либо вообще опускаемых, как не вписывающихся в привычные рамки интерпретаций. Особо нам импонирует позиция отечественных философов, делающих ставку на методологическое мышление, которое, производя синтез рациональности в новых условиях, порождает и новые формы человеческого мышления и деятельности, основанные на признании первичной ценности разума над другими формами познания. В этом плане перспективные стратегии науки ближайшего будущего связываются с необходимостью изменения самой концепции понимания науки, форм ее осознания. Так, системный анализ образцов гуманитарного исследования, предпринятый видным российским философом B.M. Розиным способствует более глубокому пониманию специфики гуманитарной науки в ее основных характеристиках (установка на понимание, зависимость позиции исследователя от ценностей и видения, рефлексивная природа гуманитарного знания, стремление гуманитария иметь дело с целостной личностью и др.) [5] .

Иными словами, на общем фоне фундаментальной проблематики демаркации научного и ненаучного знания вопрос о границах науки и других форм знания становится одним из наиболее актуальных вопросов исследовательской деятельности ученых, перемещаясь в центр современной гносеологии.

Четвертый аспект задачи рефлексии современного рацио связан с тенденцией междисциплинарного взаимодействия наук о познании, расширением сферы изучения многообразных связей познания с иными формами культуры и социальности, в которую попадает взаимоотношение науки со всем комплексом вненаучного, «другого», знания. В русле признания неэффективности строго интерналистского подхода к познанию и признания невозможности «дистиллировать» сознание от всех нерациональных моментов заявили о себе ряд новых подходов (допускается расширение понятия «знание» в направлении его совпадения с понятием «жизни», концепция нетрадиционной науки с включением в современное науковедение наряду с гуманитарными и социальными науками эзотерической или сакральной науки). Эти процессы, 
в свою очередь, активизируют проблематику самополагания границ науки, генерирования альтернативных форм знания на границах с наукой. Одновременно заметим: научные философские и методологические контроверзы, проблемным полем которых выступает наука, научная рациональность, сопровождаются острой критикой в адрес неклассических «новомодных веяний».

На наш взгляд, философская рефлексия границ науки и «другого» знания несомненно актуальна и для понимания того факта, что нет мира «чистой» науки и «чистого» рационализма. «Мир науки» включает в себя все многообразие других, отличных от «чисто научных» форм знания (миф, теологические представления, интуицию, мистический, эзотерический опыт), равно как и все формы знания в известной мере рациональны (последняя рождается вместе с разумом). - Везде мы наблюдаем метаморфоз, взаимопревращение, взаимозаменяемость, восполняемость всех форм знания на границах науки и ненауки [6, с. 19]. Подчеркнем, что мы исходим из системной природы культуры, ее понимания как целостной и органической системы, обладающей внутренней определенностью ценностно-иерархических взаимоотношений, и включающей в себя (помимо ценностной доминанты) множество подсистемных субкультурных образований. А также трактовки культуры в качестве открытой и саморазвивающейся системы в пространстве и времени жизнедеятельности человечества, конкретных сообществ и живых людей, находящих нужные жизненные ориентиры в субкультурных общностях, в недрах (и на почве) которых возникают и развиваются самые разные нетрадиционные (вплоть до экзотических) духовные формы [7, с.17] .

Поэтому, совсем, по-видимому, не случайно современные тенденции, касающиеся рефлексии разума, проблематики рациональности науки, связаны с отходом от жестких позитивистских критериев демаркации науки и ненауки, с расшатыванием «перегородок» между наукой и другими сферами духовного производства в направлении последующего слома этих барьеров. Все чаще достоверность познания (в том числе и научного) ищется в «жизненном мире» как сфере «непосредственно очевидного», имеющего значимость гораздо большей степени в сравнении с ценностями объективно-логических очевидностей. В контексте сказанного нам импонирует подход к результатам познавательной деятельности, который исходит из рассмотрения целостного человека со всеми субъектно-трансцендентальными и эмоционально-личностными особенностями его духовной жизни, с выводимостью свойств знания не из универсальных, «вечных» критериев рациональности, а из свойств познающего субъекта и практических контекстов его деятельности (в русле экзистенциально-антропологической традиции). В самом деле, утверждение коммуникативной природы познания, признание многомерного образа реальности, плюралистичности точек зрения создают почву для отношений дополнительности и взаимодействия между в сфере познания и деятельности.. Поскольку знание системно и взаимосвязано, то вполне резонно, что оно должно корреллировать, сопрягаться с «другим» знанием.

Для нас совершенно очевидно, что фундаментальная проблема демаркации «науки ненауки» не может быть разрешена только лишь посредством апелляции к формальным стандартам (критериям) научности - они имеют на сегодняшний день скорее не демаркационный, а нормативно-ориентирующий характер и важны преимущественно для развития «хороших» наук в качестве позитивного идеала. С учетом этого известная позитивистская радикальная новация, согласно которой в основании теоретической конструкции следует класть не серию предписывающих законов, а некое минимальное множество принципов запрета, дополненная требованием выработки «правил научной честности» (в терминологии И. Лакатоса), звучит по-прежнему актуально.

Таким образом, проблема границ знания является актуальной не только с позиции философской рефлексии разума и необходимости выработки механизмов ограничения его компетенции. В конечном счете, ее вхождение в современность резонирует с необходимостью задать кардинально иные ориентиры современного научного знания, от которых, собственно, зависит и выбор жизненных стратегий человечества. Однако осмысление данной проблемы в современной теоретическо-методологической области нельзя признать вполне удовлетворительным. Об этом свидетельствует и рост количества публикаций, их широкая векторность, и сам полемичный накал философских и методологических контроверз, посвященных проблематике рациональности науки, «другого» знания, по- 
искам оптимальных стратегий научного поиска в третьем тысячелетии. На наш взгляд, этическая и философская рефлексия границ компетенции разума жизненно необходимы для процессов реальной гуманизации науки, преодоления ее рассогласования с базисными ценностями культуры. А по большому счету для разрешения вопроса о возможном и допустимом в науке (да и в любой деятельности) в пользу самоценности жизни как таковой.

\section{Библиография:}

1. Русский толковый словарь. М: «Эксмо», 2007. С. 132.

2. Кант И. Критика чистого разума. Сочинения : в 6 т. Т. 3. - М, 1964. 590 с.

3. Петров М. К. Историко-философские исследования.-М: Российская политическая энциклопедия (РОССПЭН), 1996. 512 с.

4. Дугин А.Г. Эволюция парадигмальных оснований науки, М.: Арктогея-центр, 2002. 418 с.

5. Розин В.М. Гуманитарная наука и исследования. М, 2007. 168 с.

6. Калинина Г. Н. Границы науки и превращенные формы знания. Белгород, 2012. 292 с.

7. Калинина Г.Н. Автореф. диссертации ... д.филос. н. / 09.00.01 - теория и история культуры. Белгород: НИУ «БелГУ», 2015. 45 с.

\section{References (transliterated):}

1. Kant I. Kritika chistogo razuma. Sochineniya : v 6 t. T. 3. - M, 1964. 590 s.

2. Petrov M. K. Istoriko-filosofskie issledovaniya.-M: Rossiiskaya politicheskaya entsiklopediya (ROSSPEN), 1996. $512 \mathrm{~s}$.

3. Dugin A.G. Evolyutsiya paradigmal'nykh osnovanii nauki, M.: Arktogeya-tsentr, 2002. $418 \mathrm{~s}$.

4. Rozin V.M. Gumanitarnaya nauka i issledovaniya. M, 2007. 168 s.

5. Kalinina G. N. Granitsy nauki i prevrashchennye formy znaniya. Belgorod, 2012. 292 s.

6. Kalinina G.N. Avtoref. dissertatsii ... d.filos. n. / 09.00.01 - teoriya i istoriya kul'tury. Belgorod: NIU «BelGU», 2015. $45 \mathrm{~s}$. 